\title{
O PRINCÍPIO DA EFICIÊNCIA E O PROCEDIMENTO ADMINISTRATIVO
}

DAvi CHICósKI*

1. Considerações iniciais - 2. Noção jurídica de eficiência - 2.1. O conceito indeterminado e pluridimensional de eficiência - 2.2. Interpretação constitucional do princípio da eficiência - 3. Incidência da eficiência no procedimento administrativo - 3.1. Dicotomia processo-procedimento e a eficiência - 3.2. O problema da informalização do procedimento - 4. Conclusão

\section{Considerações iniciais}

Uma das questões que ressalta quando se estuda a eficiência como princípio norteador da Administração Pública é sua relação com o procedimento administrativo, meio pelo qual o Estado se manifesta em boa parte de suas atividades. Em razão da ideologia responsável pela inserção da eficiência como princípio constitucional - a concepção dita gerencialista de administração pública —, parece inconcebível que o procedimento administrativo burocrático, taxado de ineficiente, possa se adequar a esse novo valor insculpido no artigo 37 da Constituição. Dessa aparente dissonância entre ambas as categorias surgiram posicionamentos nos dois extremos: um, que rejeita a noção jurídica de eficiência, apontando nela apenas uma faceta do neoliberalismo; outro, que aprova essa nova administração representada pela reforma administrativa, objetivando excluir da Administração Pública os moldes preestabelecidos que "engessam" sua atuação.

Parece, entretanto, que ambas as posições são passíveis de críticas. Uma delas porque desconsidera a indeterminação do significante eficiência, cuja interpretação pode superar uma visão meramente economicista; a outra, porque esquece a finalidade que impõe a presença do procedimento administrativo como meio de exteriorização da função administrativa, qual seja, a garantia dos cidadãos.

* Pós-graduando em Direito Administrativo no Instituto de Direito Romeu Felipe Bacellar.

R. Dir. Adm., Rio de Janeiro, 237: 93-118, Jul./Set. 2004 
Nessa medida, reputa-se mais importante tentar adequar procedimento e eficiência, na busca por um sistema jurídico-administrativo que efetivamente concretize os fins preconizados pela Constituição - tanto no que tange aos direitos individuais quanto aos sociais e difusos, implicando num regime realmente democrático de direito. Assim, é numa conformação constitucional da noção jurídica de eficiência, bem como na revalorização da segurança trazida pelas formas procedimentais (enquanto meios de atingimento de fins sociais e democráticos), que se pode admitir um procedimento administrativo eficiente.

\section{Noção jurídica de eficiência}

A eficiência, sobretudo a partir do advento do Estado de Bem-estar Social, passou a ser objeto de busca incessante por parte do Estado, tendo estreita relação com a crise enfrentada por este. Nos últimos tempos ela vem sendo fortemente vinculada ao chamado modelo gerencial de administração pública, o qual pretende se opor ao modelo racional-burocrático (que se legitima pelo procedimento) justamente no que se refere à maximização dos fins preconizados pelo Estado (legitimação pelo resultado).

Claus OFFE foi um dos intelectuais de formação marxista que melhor estudou as contradições e a consequiente crise do Estado de Bem-estar Social. A seus olhos, com o acréscimo de funções destinadas à administração do Estado capitalista, entram em choque as dimensões (ou critérios de racionalidade) de respeito às regras legais e de efetividade funcional, o que leva a uma alteração do significante eficiência em relação ao modo como Max WEBER ${ }^{1}$ a concebia:

A eficiência não é aqui definida pelo respeito às regras e sim pela realização de funções e pela tentativa de provocar efeitos. Sob o ponto de vista do ordenamento de suas tarefas concretas, a administração precisa organizar de forma variável seus próprios inputs e premissas. Ela é eficiente na medida em que o faz com êxito. As premissas da ação administrativa não são mais regras que precisam ser seguidas sem restrições, e sim recursos, avaliados do ponto de vista de sua adequação para certas tarefas. ${ }^{2}$

1 Sobre a noção weberiana de eficiência, decorrente da racionalidade formal-burocrática, ver: CHICÓSKI, Davi. "Burocracia e Legitimação: fundamentos do procedimento administrativo eficiente". In: A\&C Revista de Direito Administrativo e Constitucional. Belo Horizonte: Fórum, $\mathrm{n}$. 15, p. 19-38, jan./mar., 2004, p. 22-25.

2 OFFE, Claus. Problemas Estruturais do Estado Capitalista. Tradução de Bárbara Freitag. Rio de Janeiro: Tempo Brasileiro, 1984, p. 221. Para OFFE, "a racionalidade burocrática não assegura, e possivelmente contraria, a racionalidade política do sistema nas condições do Estado de bem-estar capitalista. A dominação burocrática não é, como acreditava Weber, o critério estrutural irreversível de todas as sociedades futuras, mas está vinculada a certas fases históricas e pode ser transcendida, na perspectiva de uma racionalidade sistêmica de nível superior. Os dois critérios de racionalidade só são congruentes sob condições sociais nas quais a aplicação fiel de regras abstratas baste para 
Daí que o Welfare State capitalista, na visão do autor, cai em contradição ao exigir da Administração, ao mesmo tempo, o cumprimento das normas previamente estabelecidas e a satisfação de resultados ou metas. "O ambiente não permite ao sistema administrativo desenvolver completamente aquele esquema normativo de racionalidade tecnológica, que o mesmo ambiente exige". ${ }^{3}$

É em razão desta contradição, descrita acima segundo o entendimento de Claus OFFE, e da tentativa de inclusão de uma racionalidade instrumental que decorreram as reformas do Estado de Bem-estar Social, as quais, em regra, vêm ganhando a denominação de neoliberais. ${ }^{4}$

No Brasil, Luiz Carlos Bresser PEREIRA, um dos maiores críticos do modelo burocrático, entusiasta e colaborador das reformas administrativas da década de 90 , entende da seguinte forma a dissonância entre eficiência e procedimentos burocráticos:

Foi um grande progresso o surgimento, no século XIX, de uma administração pública burocrática em substituição às formas patrimonialistas de administrar o Estado. Weber (1922), o principal analista desse processo, destacou com muita ênfase a superioridade da autoridade racional-legal sobre o poder patrimonialista. Apesar disso, quando, no século XX, o Estado ampliou seu papel social e econômico, a estratégia básica adotada pela administração pública burocrática - o controle hierárquico e formalista dos procedimentos - provou ser inadequada. Essa estratégia podia talvez evitar a corrupção e o nepotismo, mas era lenta, cara, ineficiente. Ela fazia sentido no tempo do Estado liberal do século XVIII (...). Mas era uma estratégia que já não fazia sentido, uma vez que o Estado havia acrescentado às suas funções o papel de provedor de educação pública, de saúde pública, de cultura pública, de seguridade social, de incentivos à ciência e à tecnologia, de investimentos em infra-estrutura, de proteção ao meio ambiente. ${ }^{5}$

A Emenda Constitucional n. 19/98 surgiu justamente como positivação dessa concepção gerencial, através da qual, conforme precisos ensinamentos de Caio

simultaneamente preencher as funções sociais que cabem ao subsistema da administração estatal". Ibidem, p. 218.

3 Ibidem, p. 221-3.

4 É interessante observar que o neoliberalismo surge em detrimento da noção de segurança jurídica, de tal forma que o Direito se torna um entrave ao "cumprimento das metas", conforme disserta Emerson GABARDO: "inversamente ao período precedente, o capitalismo neoliberal não precisa mais de segurança. Ao contrário, locupleta-se de sua ausência. E, dessa forma ocorrendo, mais do que um instrumento capitalista (como sempre foi entendido), o direito, notadamente constitucional, passa a exercer uma função reacionária". GABARDO. Eficiência e Legitimidade do Estado: uma análise das estruturas simbólicas do direito político. Barueri: Manole, 2003 p. 175. Cf. Ibidem, p. 171-85.

5 PEREIRA, Luiz Carlos Bresser. "Gestão do setor público: estratégia e estrutura para um novo Estado”. In: PEREIRA. Luiz Carlos Bresser; SPINK, Peter (orgs.). Reforma do Estado e Administração Pública Gerencial. 4. ed. Rio de Janeiro: Fundação Getúlio Vargas, 1998, p. 26. 
TÁCITO, "estimula-se a descentralização do aparelho do Estado, com ênfase nos contratos de gestão e na maior cooperação entre a União, Estados e Municípios", valorizando-se, além disso, a participação dos usuários na Administração Pública. ${ }^{6}$ Nas palavras do autor, a evolução histórica do direito público brasileiro retrata um movimento pendular, através do qual, atualmente, o Estado volta a ceder espaço à iniciativa privada, "embora subsistente a supervisão administrativa, em resguardo da finalidade pública"?

Já numa postura contrária ao modelo "neoliberal", legitimada unicamente pelo eficientismo, Manoel Eduardo Camargo e GOMES assevera que a legitimação perde "sua natureza política e social, em troca de critérios de avaliação estritamente econômicos" ${ }^{8}$ Em sua compreensão, o neoliberalismo veste uma "pele de cordeiro", no seguinte sentido:

A ideologia, na forma de propaganda simplificadora, do Estado incompetente, ineficiente, corrupto, letárgico, obeso e de um mercado austero, ágil, eficiente, probo, voltado para a qualidade total, é utilizado em dois sentidos: de um lado, legitima importantes itens da pauta neoliberal; de outro, ampliando enormemente o déficit de legitimação política do Estado, reduz seu custo, legitimando o modelo preconizado pelos neoliberais. $O$ Estado que tudo prometia e pouco cumpria é deslegitimado para legitimar um Estado que tão pouco promete e, por isso, aparenta tudo cumprir. ${ }^{9}$

Nos limites aqui propostos em relação e essa discussão, impende afirmar que, a partir do momento em que se aborda o problema sob o prisma do sistema constitucional, torna-se superficial o antagonismo entre procedimento e eficiência. Nesse sentido, é necessário considerar alguns aspectos da eficiência, procurando encontrar nela uma noção juridicamente relevante e, especificamente, válida para uma administração que atua por meio dos procedimentos.

\subsection{O conceito indeterminado e pluridimensional de eficiência}

Primeiramente, cumpre observar a eficiência como um dentre os diversos conceitos indeterminados, largamente utilizados pelo Direito Administrativo, na

6 TÁCITO. Caio. "A Reforma do Estado e a Modernidade Administrativa". In: Revista de Direito Administrativo. Rio de Janeiro: Renovar, n. 215, p. 1-7, jan./mar., 1999, p. 4.

7 Ibidem, p. 2. Cf. TÁCITO, Caio. "O Retorno do Pêndulo: Serviço Público e Empresa Privada. O Exemplo Brasileiro". In: Revista de Direito Administrativo. Rio de Janeiro: Renovar, n. 202, p. 1-10, out./dez., 1995.

8 GOMES, Manoel Eduardo Alves de Camargo e. "Apontamentos sobre alguns impactos do projeto neoliberal no processo de formação de tutelas jurídico-políticas". In: MARQUES FILHO, Agostinho Ramalho; et. al. Direito e Neoliberalismo: elementos para uma leitura interdisciplinar. Curitiba: EDIBEJ, 1996, p. 129.

9 lbidem, p. 127-8. 
medida em que "se apresentam ao legislador como um instrumento privilegiado para a atribuição de certo tipo de competências às autoridades administrativas para que estas possam reagir a tempo e de modo adequado aos imponderáveis da vida administrativa". ${ }^{10} \mathrm{O}$ que importa em dizer que sua definição exige maior atividade interpretativa, porquanto discricionariedade ou margem livre de apreciação ${ }^{11}$ não podem divergir do que estabelece o sistema jurídico, considerado em sua totalidade. Não é por outra razão que o Professor Celso Antônio Bandeira de MELLO, ao versar sobre controle jurisdicional, enfatiza que a discricionariedade, antes de um poder, é um dever, atribuído à Administração Pública do Estado de Direito para que esta cumpra sua função - qual seja, a função administrativa. ${ }^{12} \mathrm{Na}$ perspectiva do Direito brasileiro, essa afirmação significa consonância entre a determinação do conceito eficiência e os ditames da Constituição de 1988, marcadamente social e democrática. ${ }^{13}$ Passemos, então, a delimitar o conceito pluridimensional de eficiência.

João Carlos Simões Gonçalves LOUREIRO, após comparar a noção jurídica de eficiência com os conceitos de produtividade, racionalização, eficácia e princípio do bom andamento (positivado na Constituição Italiana), opta por um superconceito (Oberbegriff), capaz de caracterizar sua pluridimensionalidade ${ }^{14}$, do qual ele extrai basicamente quatro dimensões (eficácia, otimização, celeridade e economia):

1) Eficiência significa, em primeiro lugar, a realização eficaz de fins prédados (eficácia na realização dos fins). Num plano global ou macroscópico, está em causa a eficácia da Administração como um todo; num plano

10 SOUSA, António Francisco de. "Os 'Conceitos Legais Indeterminados' no Direito Administrativo Alemão". In: Revista de Direito Administrativo. Rio de Janeiro: Fundação Getúlio Vargas, v. 166, p. 276-91, out./dez., 1986.

11 Cf. ibidem, p. 285-91.

12 Cf. MELLO, Celso Antônio Bandeira de. Discricionariedade e Controle Jurisdicional. 2. ed. 4. tiragem. São Paulo: Malheiros, 2000, p. 13-6. Para o autor: "pode-se dar como certo que a discricionariedade jamais poderia ser entendida como margem de liberdade que obstasse o controlador (interno ou externo), da legalidade do ato de verificar se a intelecção das palavras normativas, efetuada pelo agente administrativo ao aplicar a lei, foi ou não desdobrante do campo significativo possível daquelas palavras (...). Ibidem, p. 31 .

13 Para GABARDO, "a eficiência deve ser buscada dentro do regime e não mediante a sua mutação, a fim de que seja resguardada a segurança jurídica na forma como protegida pela democracia social e não pela restrita democracia neoliberal. Qualquer alteração legislativa, quando necessária (e a mudança é natural e adequada ao acompanhamento da evolução social), deverá respeitar o princípio da superioridade constitucional". GABARDO. Eficiência..., p. 184.

$14 \mathrm{O}$ autor afirma que: "este rápido excurso pela eficiência e figuras afins, alerta-nos para as dificuldades e para alguns equívocos da noção; sendo de recusar um conceito meramente tecnocrático de eficiência, de matriz economicista (...). A eficiência deve parecer hoje, na literatura jurídica, como um superconceito (Oberbegriff) caracterizado pela nota da pluridimensionalidade". LOUREIRO, João Carlos Simões Gonçalves. "O Procedimento Administrativo entre a Eficiência e a Garantia dos Particulares: algumas consideraçōes". In: Boletim da Faculdade de Direito de Coimbra. Coimbra: Coimbra Editora, 1995, p.132-3. 
mesoscópico, a eficiência (eficácia) aparece como a realização dos interesses públicos secundários prosseguidos por uma determinada organização que integra a Administração Pública; num plano microscópio, a eficácia significa a realização concreta e particular dos fins pré-dados, através da intervenção do(s) agente(s) administrativo(s) legitimado(s) para a decisão. Assim, uma situação de défice de execução das actividades administrativas equivale a uma não realização da eficiência ou, se preferirmos, a um estado de inefectividade.

2) Numa segunda acepção, a eficiência surge como o modo de realização óptima dos fins da administração: parte-se de um conceito formal de eficiência, que se traduz numa relação meios-fins. (...) [Pretende-se] que o legislador e o administrador actuem de acordo com uma exigência de optimização e entre as opções possíveis escolham a opção óptima. Movemo-nos no campo da racionalidade teleológica (...).

3) Numa terceira acepção, a eficiência designa as exigências de celeridade por que se deve pautar a Administração. Neste sentido, é um dos fins a ser maximizado ou obtido com os menores custos, ao lado, p. ex., da garantia dos particulares.

4) Por último, há quem empregue o termo eficiência para se referir ao princípio da economia. ${ }^{15}$

Emerson GABARDO também estuda a eficiência e seus conceitos afins, asseverando, quanto às concepções de racionalização, que se trata de um "processo de busca do modo ótimo (sentido idealístico) ou do melhor modo possível (sentido utilitarista) na realização do fim". O autor ainda observa que a racionalização, num sentido alargado, "torna-se sinônimo da própria eficiência (ao invés de ser um instrumento de seu alcance), na medida em que ser eficiente (no caso, ser racional) pode ser entendido, simplesmente, como tomar a eficiência na qualidade de objetivo (racionalizar)". 16

Além disso, GABARDO expõe a relevância adquirida pela noção de produtividade, a qual também se vincula ao conceito de eficiência e tem, dentre outros, os seguintes sentidos:

15 Ibidem, p. 131-2. No que se refere à segunda acepção proposta por LOUREIRO, observa-se que ela vai além da exigência de critério técnico a que se referia Hely Lopes MEIRELLES, em sua exposição sobre o dever de eficiência, eis que, mesmo em havendo diferentes alternativas técnicas possíveis, o administrador deverá escolher a ótima. De fato, MEIRELLES segue o entendimento de que o administrador pode optar dentre as 'alternativas técnicas": "Realmente, não cabe à Administração decidir por critério leigo quando há critério técnico solucionando o assunto. O que pode haver é opção da administração por uma 'alternativa técnica' quando várias lhe são apresentadas como aptas para solucionar o caso em exame." MEIRELLES, Hely Lopes. Direito Administrativo Brasileiro. 22. ed. São Paulo: Malheiros, 1997, p. 91.

16 GABARDO. Emerson. Principio Constitucional da Eficiência Administrativa. São Paulo: Dialética, 2002, p. 27. 
1. equivalente, 2. mais amplo ou 3. mais restrito que o de eficiência (esta entendida como resultante de uma relação entre meios e fins). Na primeira acepção, é descrita através da relação entre o produto final e os fatores utilizados na produção (meios/custos); na segunda, a produtividade é consequiência da soma entre eficácia (sendo esta efeito da divisão do produto final pelo objetivo/meta) e eficiência (cuja fração tem como dividendo o produto final e divisor os meios/custos); e na terceira, a produtividade ou rendimento é analisada como o próprio produto. ${ }^{17}$

Já em relação à economicidade e à celeridade como sinônimos de eficiência, o mesmo autor adverte que, em ambos os casos, trata-se de "casos claros de redução do conceito, ao que, em regra, somente é apontado como um dos seus elementos. Tem-se, portanto, a contenção do condicionado em um de seus condicionantes". A economicidade "tem um sentido específico de tornar o trabalho o mais produtivo possível, adquirindo a maior quantidade de riqueza com o mínimo de dispêndio de energia". ${ }^{18}$ Já o conceito de celeridade "denota grande popularidade no direito administrativo, para o qual significa a aplicação de 'formas expeditas de decisão' (segundo Loureiro), ou, ainda, em um sentido menos procedimentalista, maior rapidez nas ações da Administração. No entanto, é certo que o elemento 'tempo' não compreende todos os aspectos, seja da economicidade, seja da eficiência". ${ }^{19}$

Por fim, ainda como face da eficiência, GABARDO alude à eficiência jurídica, de conteúdo também indefinido e "que pode significar, exemplificativamente: eficácia jurídica (aptidão para produzir, em maior ou menor grau, efeitos jurídicos), eficácia social ou efetividade (efetiva conduta acorde com a prevista pela norma) ou ter um conceito próprio, referente ao sucesso da norma na obtenção dos resultados". ${ }^{20}$

\subsection{Interpretação constitucional do princípio da eficiência}

Com todos os significados que a eficiência pode assumir, é possível perceber a dificuldade de sua apreensão, mesmo dentro dos limites do Direito. Assim, enquanto conceito indeterminado, é necessário, seguindo o entendimento precursor de Romeu Felipe BACELLAR FILHO ${ }^{21}$, conformá-la dentro dos parâmetros fixados constitucionalmente para que se possa definir sua abrangência e sua relação com o procedimento administrativo. Não cabe aqui aprofundar-se para saber se a eficiência deveria ou não ser princípio constitucional de Direito Administrativo ${ }^{22}$, pois, para

17 Ibidem, p. $27-8$

18 Ibidem, p. 28.

19 lbidem, p. 29.

20 Ibidem, p. 30.

21 Cf.: BACEllar FILHO, Romeu Felipe. Princípios Constitucionais do Processo Administrativo Disciplinar. São Paulo: Max Limonad, 1998, p. 193-7.

22 Nesse sentido ver GABARDO, Princípio..., p. 73-99. 
tanto, seria necessário abordar as diferentes concepções de princípio, válidas para o sistema jurídico e para as teorias constitucionais, mas distantes do objetivo proposto. Logo, partindo da premissa de que a eficiência é princípio constitucional da Administração Pública, de forma explícita desde a Emenda Constitucional n. ${ }^{\circ} 19 / 98$, mas desde antes passível de ser extraída do texto constitucional, resta saber se ela é ou não importante.

Com efeito, embora explicitamente definida como princípio a partir de 1998, como mote da reforma do Estado, a eficiência já podia ser extraída do texto original da Constituição, como nos lembra Paulo MODESTO: "O texto original da Constituição Federal de 1988, ora de forma explícita, ora de forma implícita, refere à exigência de eficiência como uma obrigação constitucional da administração pública em diversas normas", podendo-se citar como exemplos os artigos 74 e 144 (de forma explícita) e os artigos 70 e 71 (de forma implícita). O autor ainda lembra que já havia menções sobre a necessidade de atuação eficiente do Estado tanto na doutrina quanto na jurisprudência. ${ }^{23}$

Em relação à doutrina, Hely Lopes MEIRELLES já se referia ao dever de eficiência, que, em suas palavras, é dever imposto ao agente público, para que este realize "suas atribuições com presteza, perfeição e rendimento funcional". Para ele, trata-se do "mais moderno princípio da função administrativa, que já não se contenta em ser desempenhada apenas com legalidade, exigindo resultados positivos para o serviço público e satisfatório atendimento das necessidades da comunidade e de seus membros". ${ }^{24}$

Se por um lado alguns autores, entusiastas da reforma do Estado e do modelo gerencial de administração, consideram o princípio da eficiência a panacéia dos males da Administração Pública, outros temem sua elevação ao status de princípio positivado constitucionalmente ou desconsideram sua importância. Egon Bockmann MOREIRA, numa crítica preliminar ao princípio da eficiência, que para ele importaria numa visão privatística da Administração Pública, assevera:

A Emenda n. 19/98 pretendeu outorgar à Administração Pública uma máxima não jurídica, típica da administração e economia, que se referem basicamente ao desempenho de entes privados. Para tais ciências, o conceito do termo "eficiência" pertence à relação entre trabalho, tempo, investimento e resultado lucrativo obtido em determinada ação empresarial; é o vínculo entre custos e produto final (...).

Não se trata [a eficiência] de princípio jurídico, muito menos poderia ser alçado à condição de norma constitucional. Sua inserção não gerará nenhuma novidade ou benefício concreto.

23 MODESTO. Paulo. Notas para um Debate sabre o Princípio Constitucional da Eficiência. In: http.//www.jus.com.br/doutrina/prefici3.html". Acesso em 20/08/2002.

24 MEIRELLES, op. cit., p. 90. 
Ademais, o autor reforça seu entendimento ao afirmar que uma conduta eficiente só pode ser auferida mediante normas que estabeleçam precisa e minuciosamente os resultados a serem obtidos pela Administração, e que, portanto, eficiência não pode ser vista nos moldes genéricos e abstratos de um princípio. ${ }^{25}$

Celso Antônio Bandeira de MELLO, por seu turno, não vê grande relevância na inclusão do princípio da eficiência na Constituição da República, conforme se denota do seguinte excerto:

Quanto ao princípio da eficiência, não há nada a dizer sobre ele. Trata-se, evidentemente, de algo mais do que desejável. Contudo, é juridicamente tão fluido e de tão difícil controle ao lume do Direito, que mais parece um simples adorno agregado ao art. 37 ou o extravasamento de uma aspiração dos que buliram no texto. De toda sorte, o fato é que tal princípio não pode ser concebido (entre nós nunca é demais fazer ressalvas óbvias) senão na intimidade do princípio da legalidade, pois jamais uma suposta busca de eficiência justificaria postergação daquele que é o dever administrativo por excelência. ${ }^{26}$

Não obstante o valor das posições em contrário, é preferível adotar o entendimento de que o princípio da eficiência, se por um lado não deve sobrepor-se aos ditames da legalidade, também não pode ser desacreditado, pois a atuação estatal eficiente, além de também contribuir para a legitimação do poder ${ }^{27}$, acaba sendo um aspecto da própria legalidade, quando observada de um ângulo material, e corrobora, assim, para a manutenção do próprio Estado Social e Democrático de Direito. Um mínimo de eficiência é necessário para que o Estado atue na persecução de fins sociais, ou, nas palavras de LOUREIRO, "um mínimo de eficiência é uma exigência que integra a idéia de justiça". ${ }^{28}$ Nesse sentido, MODESTO tem o seguinte posicionamento:

Em verdade, ao contrário de contrastar com o princípio da legalidade, ou legitimar sua atenuação, penso que o princípio da eficiência pode ser percebido como componente da própria legalidade, percebida sob um ângulo material e não apenas formal. Refiro-me à legalidade material explorada

25 MOREIRA, Egon Bockmann. "Processo Administrativo e Princípiọ da Eficiência". In: SUNFELD, Carlos Ari: MUÑOZ, Guillermo Andrés (Coords.). As leis de processo administrativo: Lei Federal 9.784/99 e Lei Paulista 10.177/98. São Paulo: Malheiros, 2000. p. 325-6.

26 MELlo, Celso Antônio Bandeira de. Curso de Direito Administrativo. $12^{\mathrm{a}}$ ed. São Paulo: Malheiros, 2002. p. 92.

27 Para compreender a eficiência como mecanismo simbólico da legitimidade estatal, é importante recorrer ao ensaio empreendido por GABARDO, para quem, com o advento da modernidade, "a legitimidade do poder deixa de seu um mero a priori, passando a depender da capacidade individual e, portanto, da eficiência do soberano na condução dos negócios públicos". GABARDO, Eficiência..., p. 195. Cf.: Ibidem, pp. 56-9.

28 LOUREIRO, op. cit., p. 147. 
excelentemente entre nós, há anos, pelo Prof. CELSO ANTÔNIO BANDEIRA DE MELLO, nomeadamente quanto trata do dever de atuação ótima ou excelente do administrador nas hipóteses de discricionariedade (cf. Discricionariedade e Controle Judicial. São Paulo, Malheiros, 1992, pp. 33-36). ${ }^{29}$

Com efeito, BANDEIRA DE MELLO ensina que o objetivo do legislador, ao redigir norma que confira discricionariedade à atividade administrativa, é precisamente o de que "só se tome a providência excelente, e não a providência sofrível e eventualmente ruim, porque, se não fosse por isso, ela teria sido redigida vinculadamente". 30

Por tais motivos, ao se encarar a eficiência como conceito jurídico indeterminado, o objetivo é interpretá-la segundo o sistema jurídico erigido sob os princípios constitucionais do Estado social, democrático e de direito, a fim de que se the extraiam, mesmo numa perspectiva de discricionariedade, benefícios concretos à sociedade, e não apenas às classes econômico-sociais dominantes - as quais influenciaram na sua positivação constitucional, através da Emenda n. ${ }^{\circ}$ 19/98. LOUREIRO, nesse sentido, é prudente ao observar que "a tendência crescente vai no sentido de tomar em conta as lições da eficiência, introduzindo-a nas ponderações jurídicas. Trata-se de um princípio de realidade que, no entanto, não deve subverter a específica intencionalidade normativa prosseguida com o Direito". ${ }^{31}$

Diante disso, podemos salientar que a eficiência não é um mal em si, o qual pode destruir todo o caminhar do Estado rumo aos direitos sociais. Ao contrário, em alguns aspectos, é justamente a ineficiência que pode sacrificar direitos tais como o de educação, saúde ou seguridade social. O que se deve observar, porém, é uma leitura do princípio da eficiência em conformidade com os demais princípios constitucionais e, enfim, com o sistema jurídico do Estado Social e Democrático de Direito. É indispensável, portanto, uma interpretação conforme a Constituição, e não segundo experiências oriundas do setor privado. Nesse sentido, BACELLAR FILHO ensina:

29 MODESTO, op cit. O professor ainda complementa seu raciocínio afirmando que: "Para alguns, entusiastas da novidade do princípio, este marca um novo momento da administração pública, caracterizado pela ruptura com o modelo de 'organização auto-referida', pois permitiria que a administração pública cuidasse menos dos meios e processos e mais dos resultados externos do seu labor. Para outros, a consagração do princípio da eficiência significa uma vitória da ideologia neoliberal, traduzindo um perigoso retrocesso na ordem constitucional inaugurada em 1988, capaz de provocar um grave abalo de suas estruturas e contribuir para o rompimento do Estado de Direito. Exageros à parte, com pleno respeito dos que pensam em contrário, entendo que essas duas leituras da lei maior esquecem o essencial, nunca houve autorização constitucional para uma administração pública ineficiente", Ibidem.

30 MELLO, Discricionariedade..., p. 35. Mais adiante, o autor afirma: "a boa intelecção da regra de Direito impõe reconhecer que o campo de liberdade administrativa decorrente das normas que prefiguram discrição é muito mais angusto do que habitualmente se admite, seja porque a situação concreta é que lhe dará sua verdadeira dimensão, reduzindo-o muito, seja porque a Administração Pública está sujeita ao "dever de boa administração"'. Ibidem, pp. 44-5.

31 LOUREIRO, op. cit., p. 149. 
Qualquer significado a ser atribuído a este princípio terá de passar pelo exame da conformidade com a Constituição. Enquanto produto do exercício da competência reformadora, o princípio constitucional da eficiência deve ser interpretado e aplicado, observando-se o núcleo constitucional integrante das cláusulas pétreas (art. $60, \S 4^{\circ}$ ). Daqui emergem duas conseqüências: i) o princípio constitucional da eficiência deve sofrer um processo contínuo de interpretação conforme a Constituição, a fim de evitar rupturas ou fraudes constitucionais que atentem contra a identidade da Lei Fundamental, ii) respeitado o limite anterior, o princípio constitucional da eficiência ao interagir, principalmente, com os demais princípios constitucionais da Administração Pública - legalidade, impessoalidade, moralidade e publicidade - participará do mecanismo das deslocações compreensivas e da ponderação a ser levada a cabo na aplicação dos princípios ao caso concreto. ${ }^{32}$

A partir do momento em que o princípio da eficiência já está inserido no ordenamento, MOREIRA entende que ele pode contribuir para a garantia e a ampliação dos direitos sociais, porquanto o que deve imperar é uma interpretação conforme (a qual se valha das regras do legislador racional e da interpretação popular). ${ }^{33}$ Nesse passo, para ele, "será eficiente a Administração Pública que cumprir com excelência a lei e a moral, de forma impessoal e pública", concluindo que "sua existência impõe interpretação no sentido de princípio positivado em exclusivo benefício do cidadão, ampliativo de seus direitos, configurando mais um dever e parâmetro de controle da atividade administrativa pública" 34

Para Paulo MODESTO, o princípio da eficiência pode ser definido "como a exigência jurídica, imposta aos exercentes de função administrativa, ou simplesmente aos que manipulam recursos públicos vinculados de subvenção ou fomento, de atuação idônea, econômica e satisfatória na realização de finalidades públicas assinaladas por lei, ato ou contrato de direito público". Ademais, conforme frisa o autor, a eficiência significa um novo mecanismo de legitimação do direito público, quando aplicada à Administração, pois permite um controle mais efetivo da competência discricionária de seus agentes. ${ }^{35}$

Noutros termos, FAZZIO JÚNIOR vê o dever de bem administrar como decorrência do princípio republicano, "segundo o qual quem administra gere o que pertence à sociedade", e lembra que "eficiência é o atributo essencial que justifica a existência de uma organização administrativa. A Administração Pública não é um ornamento nem existe para não funcionar. Seu fim justificado é a medida de sua

32 BACELLAR FILHO, op. cit., p. 193-4. Na interação recíproca dos princípios constitucionais "ocorrem deslocações compreensíveis, ou seja, modificações no entendimento do conteúdo de um princípio podem produzir reflexos na compreensão de outro". Ibidem, p. 148.

33 MOREIRA. Processo Administrativo e Princípio da Eficiência..., op. cit., p. 329.

34 Ibidem, p. 332.

35 MODESTO, op. cit. 
atuação" ${ }^{36}$ Finaliza dizendo que "administrar com eficiência é maximizar o resultado social colimado pela lei". ${ }^{37}$

O princípio constitucional da eficiência denota dois aspectos, conforme entendimento de Maria Sylvia Zanella DI PIETRO: "pode ser considerado em relação ao modo de atuação do agente público, do qual se espera o melhor desempenho possível de suas atribuições, para lograr os melhores resultados; e em relação ao modo de organizar, estruturar, disciplinar a Administração Pública, também com o objetivo de alcançar os melhores resultados na prestação do serviço público", ${ }^{38}$ sendo que é sobretudo nesse segundo aspecto que há íntima relação com o procedimento administrativo, dada a necessidade de previsibilidade da atuação administrativa para otimizar o resultado social. A mesma autora complementa seu entendimento ao defender que "a eficiência é princípio que se soma aos demais princípios impostos à Administração, não podendo sobrepor-se a nenhum deles, especialmente ao da legalidade, sob pena de sérios riscos à segurança jurídica e ao próprio Estado de Direito". 39

Emerson GABARDO, um dos autores que melhor estudou o princípio constitucional da eficiência administrativa, ensina como este deve ser interpretado conforme a Constituição, de modo que reproduzimos seu posicionamento, como conclusão do presente tópico deste trabalho:

Não deve ser esquecida, quando aplicado o princípio em questão, a natureza compromissória, democrática e dirigente da Constituição Federal de 1988. Dessa forma, muito pouca relevância será relegada aos motivos ensejadores da inclusão da eficiência na Constituição. Bem se sabe que no Plano Diretor da Reforma do Aparelho do Estado, que deu origem a tal inclusão, a idéia predominante era a desconstitucionalização, rumo a um neoliberalismo debilitado na forma da Administração Gerencial. Na aplicação prática do princípio, certamente que a perspectiva deve alterar-se, rumo à democracia-social, que, nesse sentido, torna-se compatível com a Constituição vigente (...). Ademais, não se pode cair no erro de interpretar o princípio da eficiência de acordo com a legislação infraconstitucional (mais específica e tecnocrática), na medida em que isto causaria a inversão do necessário processo de "filtragem", numa clara contramão hermenêutica. ${ }^{40}$

36 FAZZIO JÚNIOR, Waldo. Fundamentos de Direito Administrativo. São Paulo: Atlas, 2001, p. 23.

37 Ibidem, p. 24.

38 DI PIETRO, Maria Sílvia Zanella. Direito Administrativo. 14. ed. São Paulo: Atlas, 2002, p. 83 .

39 Ibidem, p. 84.

40 GABARDO, Princípio..., p. 89. O Prof. Emerson GABARDO resume seu entendimento explicando que "o princípio da eficiência é setorial, pois refere-se exclusivamente à Administração Pública, mas está diretamente ligado ao princípio da eficiência do Estado como vetor geral (de caráter ético) do sistema constitucional. Dessa forma, tão importante quanto a relação com os demais 


\section{Incidência da eficiência no procedimento administrativo}

Estabelecidas as premissas necessárias, cumpre estudar, numa perspectiva vinculada sobretudo ao Direito brasileiro, alguns aspectos relacionados à tentativa de equilíbrio entre o procedimento administrativo e a eficiência. O trabalho será enfrentado sob dois aspectos: primeiro, defendendo alguns limites à eficiência, notadamente quando se exige a garantia do cidadão por meio do processo administrativo; depois, considerando a questão da informalização do procedimento, que vem sendo compreendida como a maneira por excelência de torná-lo eficiente.

\subsection{Dicotomia processo-procedimento e a eficiência}

Para que se possa discorrer sobre a necessidade de equilíbrio entre a eficiência e o procedimento administrativo, é importante, primeiramente, pressupor uma distinção entre procedimento e processo administrativos. Trata-se de uma dicotomia que causa forte divergência na doutrina, cujos diferentes posicionamentos foram excelentemente analisados por MOREIRA. ${ }^{41}$ Não interessa, porém, ir a fundo nesse debate terminológico, mas de relevantes consequiências práticas. Inobstante as divergências, pode-se seguir o entendimento de que procedimento administrativo é a sucessão ordenada de atos e fatos jurídicos destinados a um fim almejado pela Administração Pública. Processo administrativo, por sua vez, é espécie do gênero procedimento administrativo, que se forma sempre que há a participação de interessados em contraditório, como defende BACELLAR FILHO. ${ }^{42}$

No Brasil, partindo notadamente do pensamento de Feliciano BENVENUTI, a Professora Odete MEDAUAR, após analisar diversos critérios de distinção entre processo e procedimento na seara do Direito Administrativo, defendeu o que ora adotamos, senão vejamos:

Essa evolução culmina, principalmente, na concepção do procedimento-gênero, como representação da passagem do poder em ato. Nesse enfoque, $o$ procedimento consiste na sucessão necessária de atos encadeados entre si que antecede e prepara um ato final. $O$ procedimento se expressa como processo se for prevista também a cooperação de sujeitos, sob prisma contraditório. ${ }^{43}$

princípios da Administração Pública, que não é só externa, mas intrínseca, é a submissão do princípio da eficiência aos princípios estruturantes (ou fundamentais) do sistema constitucional, entre os quais se destaca o princípio do Estado Social e Democrático de Direito". Ibidem, p. 89-90.

41 Cf. MOREIRA, Egon Bockmann. Processo Administrativo: Princ ípios Constitucionais e a Lei 9.784/99. São Paulo: Malheiros, 2000, p. 29-53.

42 BACELLAR FILHO, op. cit., p. 45-8.

43 MEDAUAR, Odete. A Processualidade no Direito Administrativo. São Paulo: Revista dos Tribunais, 1993, p. 40-1. 
Na mesma linha, BACELLAR FILHO explica como ocorre a formação do processo administrativo, nos seguintes termos:

Quando à competência adiciona-se a colaboração de sujeitos e contraditório, o procedimento expressa-se como processo. O processo administrativo é forma de "exteriorização da função administrativa" (procedimento administrativo) qualificado pela participação dos interessados em contraditório, imposto diante da circunstância de se tratar de procedimentos celebrados em preparação a algum provimento (ato de poder imperativo por natureza e definição). capaz de interferir na esfera jurídica das pessoas. ${ }^{44}$

Com apoio na doutrina acima exposta, pode-se ousar um paralelo entre o processo administrativo e as expectativas cognitivas, na esteira da teoria sistêmica de Niklas LUHMANN, diante da maior abertura cognitiva da espécie processo administrativo. Ou seja, quando se travar uma relação processual administrativa, o sistema jurídico não confere uma decisão única e certa para o seu desfeche, através de mera subsunção, por haver informações provenientes de interesses contrapostos, as quais surgirão gradualmente no desenrolar do processo. Assim, o sistema processual aprende o conteúdo cognitivo que os participantes, dentro de determinados limites, levam para o seu interior, transformando-o em decisão normativa. ${ }^{45}$

Seja no procedimento seja no processo, os anseios de eficiência devem condizer com os demais princípios constitucionais de direito administrativo e. sobretudo, com o princípio do Estado de Direito. Caso contrário, não haverá eficiência jurídica, mas deturpação dos valores constitucionais. "O Estado de Direito é o princípio fundamental de que derivam vários dos princípios incidentes no processo administrativo. Aliás, é um conceito que permeia todo o Direito Público, porque a sua idéia original é a de um Estado que cria o Direito e submete-se ao mesmo em função da garantia dos indivíduos contra o arbítrio". 46

Não se pode olvidar que o procedimento administrativo stricto sensu (não caracterizado pela existência de partes em contraditório) também corrobora numa perspectiva de garantia, como nos ensina BACELLAR FILHO:

A análise isolada do art. $5^{\circ}$, inc. LV, poderia levar ao entendimento segundo o qual o procedimento somente estaria elevado à garantia constitucional

44 BACELLAR FILHO, op. cit., p. 46.

45 Num desdobramento da posição de LUHMANN, conforme entendimento do Prof. Romeu Felipe BACELLAR FILHO. em aula proferida na Faculdade de Direito da UFPR, no dia 15.02.2003. Ver: CHICÓSKI, op. cit., p. 33. Para LUHMANN, o Direito constitui "um sistema normativamente fechado, mas cognitivamente aberto (...). A qualidade normativa serve à autopoiese do sistema, à sua autocontinuação diferenciada do meio ambiente. A qualidade cognitiva serve à concordância desse processo com o meio ambiente do sistema". LUHMANN. Niklas. "Die Einheit des Rechtssystems”, apud NEVES, Marcelo. A Constitucionalização Simbólica. São Paulo: Acadêmica, 1994. p. 120. Cf. ibidem, p. 119-24.

46 BACELLAR FILHO, op. cit. p. 121. 
quando inserido em um processo. Contudo, o art. $5^{\circ}$, inc. LIV garante o "devido processo legal". Vincula, portanto, o exercício do poder ao modelo procedimental estabelecido pela Constituição e pela lei. O procedimento, até quando não inserido no processo, funciona como garantia constitucional, assegurando regularidade e racionalidade do poder estatal e do dever particular. $^{47}$

No procedimento administrativo stricto sensu, nada obstante, há sensível possibilidade de influência do princípio constitucional da eficiência, pois, quanto mais célere, simples e econômico, mais acessível ele se torna à população, a qual em muitos momentos não está em contraditório, nem com a Administração nem com outros cidadãos, mas apenas requerendo a efetivação de direitos substanciais que lhe são constitucionalmente assegurados. De outro lado, como no processo administrativo abre-se margem a maior dúvida quanto ao conteúdo da decisão, a qual deve surgir da relação em contraditório dos participantes, a preocupação referente ao equilíbrio entre as garantias processuais e a necessidade de eficiência procedimental é acentuada. Tal preocupação decorre da possibilidade de que a busca por eficiência, sob determinado enfoque, enfraqueça as garantias do contraditório e da ampla defesa, constitucionalmente asseguradas.

De qualquer modo, em um ou em outro caso, se aplicado dentro dos parâmetros constitucionais, o princípio da eficiência não importa em risco aos direitos e garantias, mas, ao contrário, funciona como mais um mecanismo de controle da Administração Pública, pois esta, agora, além de agir com legalidade, deve pautar-se por uma conduta eficiente. Como defendido, a eficiência é um conceito indeterminado que, dependendo do significado a ser-lhe atribuído, pode ferir garantias ou, ao contrário, quando conforme a Constituição, ampliá-las e fortalecê-las.

O princípio do devido processo legal (de oir al interessado), nesse passo, quando aplicado ao procedimento administrativo, não é, para Agustín GORDILLO, apenas um princípio de justiça (justicia), mas também de eficiência (eficacia) "porque indudablemente asegura un mejor conocimento de los hechos y por lo tanto ayuda a una mejor administración además de a una más justa decisión". Isso porque, além da legalidade, adverte o autor, a Administração deve pautar-se por critérios de "oportunidad, mérito o conveniencia". ${ }^{48}$ Por isso, tomada nesse sentido, a eficiência não só deixa de opor-se ao princípio do devido processo legal, como passa a fazer parte dele, na medida em que proporciona um melhor conhecimento dos fatos que ensejam a decisão administrativa, tornando esta melhor e, sobretudo, mais justa.

Nas palavras de Vera Scarpinella BUENO: "temos que no domínio do Direito a idéia de procedimento eficiente configura-se como alternativa à chamada crise do Estado Social (...). Passa a ser juridicamente exigível do administrador público, com

47 Ibidem, p. 60.

48 GORDILlO, Agustín A. "La Garantía de Defensa como Principio de Eficacia en el Procedimiento Administrativo". In: Revista de Direito Público. São Paulo: Revista dos Tribunais, n. 10. p. 16-24, out./dez., 1969, p. 19. 
base em parâmetros concretos definidos em lei, a consecução de fins legítimos previamente estabelecidos e a otimização dos meios para seu alcance" ${ }^{49}$

No Brasil, Egon Bockmann MOREIRA foi um dos juristas que melhor traçou o modo como a eficiência deve ser compreendida para ampliar, e não destruir, as garantias advindas da relação processual administrativa ${ }^{50}$, ao defender que "a eficiência garante o desenvolvimento de um processo célere, simples, com finalidade predefinida, econômico e efetivo".51 Para ele, esses são os atributos da eficiência no processo administrativo, os quais, resumidamente, passamos a descrever.

1. A celeridade "impõe que os atos processuais sejam praticados no mais curto espaço de tempo possível, de forma contínua e coordenada". Ou seja, o processo administrativo não deve sofrer paralisações desnecessárias ou, então, seguir em ritmo lento. Os cidadãos inseridos na relação processual "devem cumprir os prazos preestabelecidos e praticar os atos necessários ao bom andamento do feito". A Administração Pública "não pode omitir-se ou aguardar reiterados pleitos das partes interessadas para a prática dos atos de sua competência (...)".

2. Simplicidade é a característica do processo que não se reveste de "formalidades extravagantes ou desnecessárias ao atingimento da finalidade por si visada". Tal atributo será mais bem delineado no tópico seguinte, momento em que se discutirá a informalização do procedimento administrativo. Por ora, seguindo entendimento de MOREIRA, impende afirmar que o processo "há de ser descomplicado, compreensível à população, que não deve ser constrangida a recorrer a conhecimentos científicos - quer para responder a requerimentos da Administração, quer para deduzir seus pleitos frente a ela (...)".

3. Por finalidade predefinida entende-se o dever administrativo de não gerar processos aleatórios, sem a definição de um escopo claro. $\mathrm{O}$ autor adverte que "não é possível a instalação de uma relação jurídico-processual com objetivos abstratos ou genéricos (...). As partes no processo devem ter, com absoluta clareza, ciência do fím a que se destina a relação processual (...)". Bem assim, a finalidade predefinida "limita o provimento final" porque "não será possível ato decisório que extrapole ou subestime os limites prefixados".

4. A economia processual "diz respeito ao mais alto grau de concentração e prestígio aos atos já praticados", de tal sorte que o processo siga seu curso racionalmente, sem repetição desnecessária de atos ou fases, o que, em última análise,

49 BUENO, Vera Scarpinella. "As Leis de Procedimento Administrativo: una leitura operacional do princípio constitucional da eficiência". In: SUNFELD, Carlos Ari: MUÑOS, Guillermo Andrés (Coords.). As Leis de Processo Administrativo. São Paulo: Malheiros, 2000, p. 342-63, p. 351.

50 Frise-se que o referido autor não adota posicionamento idêntico ao aqui trabalhado, no que tange à dicotomia processo-procedimento. Para ele, o termo processo se presta a designar uma relação jurídica. enquanto procedimento é apenas o rito em que se desenvolve essa relação. Cf. MOREIRA. Processo Administrativo: princípios..., p. 36. Em relação a essa discussão, Emerson GABARDO, seguindo o posicionamento adotado neste trabalho, entende " que se torna possível transpor para o gênero, sem prejuízo de conteúdo, a análise realizada por alguns autores sobre as relações entre eficiência e a espécie processo administrativo". GABARDO, Princípio..., p. 119.

51 MOREIRA, Processo Administrativo e Princípio da Eficiência..., p. 334. 
contribui para a sua celeridade..$^{52}$ Some-se a isso a lição de GABARDO, ao precisar que "ao lado do dever de anulação de um ato ineficiente está a obrigatoriedade de convalidação, quando presentes os pressupostos para tanto"..$^{53}$

5. A efetividade, finalmente, diz respeito à correta realização dos fins processuais envolvendo "a necessidade de o ordenamento dispor dos instrumentos necessários à tutela de direitos e à possibilidade de sua utilização prática". Em acréscimo, efetividade, para MOREIRA, relaciona-se à possibilidade de ampla atividade probante, desde que para fins não procrastinatórios ou despiciendos. "Por fim, o resultado do processo deve ser atingido com o mínimo dispêndio de energia, para assegurar o gozo e exercício plenos da utilidade à qual faz jus a parte vitoriosa". ${ }^{4}$

Em concordância com a definição aqui adotada, é relevante afirmar que as características acima valem não só para o processo, mas para o procedimento administrativo em geral. Logo, pode-se dizer que, "especialmente no processo administrativo (qualificado, então, pelo contraditório), tornam-se de grande importância alguns meios de colaboração no sentido de incrementação da eficiência, tais como: a garantia do direito à informação, a facilitação da vista dos autos (...), o fornecimento de fotocópias autenticadas, a publicidade efetiva e não meramente formal (...)",55 dentre outros.

Do exposto, conclui-se que no plano procedimental-processual o princípio da eficiência também deve guiar-se pelos mesmos critérios constitucionais, inspirados no Estado Social e Democrático de Direito, para que tenha validade jurídica. Sobretudo quando se tratar da espécie processo administrativo, ante a relação de fim incerto dos participantes, os atributos de eficiência devem ser no sentido de fortalecer a garantia do cidadão e reforçar o dever de que o Estado cumpra sua função administrativa.

\subsection{O problema da informalização do procedimento}

Ao se abordar a relação entre eficiência e procedimento administrativo, vem à tona a questão da informalização deste, conseqüência da assertiva segundo a qual é o formalismo o responsável pela impossibilidade de a administração agir com celeridade, simplicidade, economia e, enfim, otimização de seus resultados. Essa questão, porém, assume diversos aspectos, dependendo do conceito de informalização que se adote. Assim, enquanto alguns sustentam a necessidade de enfraquecimento das duras normas que conformam a atividade administrativa, outros, mais radicais, apregoam a própria morte do procedimento em virtude de métodos mais dinâmicos de decisão. Será analisada a primeira corrente, eis que o segundo posicionamento extrapola os limites do direito, pois, conforme nos ensina LOUREIRO, "o Direito converte-se

53 GABARDO, Princípio..., p. 126.

54 MOREIRA. Processo Administrativo e Princípio da Eficiência..., p. 339.

55 GABARDO, Princípio..., p. 126. 
num 'Nominalbegriff', sendo a idéia de validade substituída pelas noções de eficiência e de performance, tão caras a um certo quadro pós-moderno". 56

Porém, mesmo dentre aqueles que desconsideram a situação limite do não-direito, há duas perspectivas de informalidade. 1) Uma alternativa fática, que tenta fugir da vinculação jurídica, recuperando figuras como o acordo de cavalheiros. "Este modo de informalizção aparece-nos mais freqüentemente no terreno da política e da ação governamental não tanto da Administração". ${ }^{57}$ 2) Por outro lado, há a alternativa jurídica, esta sim muito influente em termos de procedimento administrativo, "para designar situações do decision-making process, que, não sendo ajurídicas nem pretendendo limitar-se a uma esfera fáctica alternativa, correspondem a formas de "soft law'", as quais permitem, através de flexibilidade e maleabilidade, " nas sombras da formalização, desenvolver a celeridade da decisão, reduzir a incerteza sobre a aprovação de um projecto e, no limite, pretendem ser alternativas jurídicas aos modos formalizados de formação e resolução da decisão". ${ }^{58}$

Quanto à alternativa fática, não há muito a dizer sobre ela, na medida em que sua aceitação seria logicamente ilegal e, assim, contrária não somente ao procedimento formalizado, mas ao próprio ordenamento jurídico. Nesse passo, vale dizer, seguindo o ensinamento de Clèmerson Merlin CLÈVE, que mesmo o "ato político, assim como o ato administrativo, a sentença e a lei, deve, para ser válido, estar de acordo com a juridicidade" ${ }^{59}$ porque, em última análise, também é expressão do poder público, e não do poder soberano, "cujo único titular é a vontade popular" ${ }^{60}$ Em acréscimo, esta primeira opção é "manifestamente inadequada para uma construção normativa e não simplesmente fática do problema em análise, sob pena de acolhermos uma ilegítima força normativa do fático, bem diferente da importância da dimensão de realidade no sistema jurídico". ${ }^{61}$.

Com efeito, é incorreto pressupor que o procedimento é uma categoria contrária à eficiência da atividade estatal. Ao invés disso, segundo Vera Scarpinella BUENO, "o ambiente criado pelo procedimento administrativo é o ideal para realizar o necessário equilíbrio entre a necessidade de celeridade, economicidade e cumprimento de metas por um lado e, por outro, realizar justiça social nas decisões administrativas que interferem na órbita dos direitos e garantias individuais dos cidadãos". ${ }^{62}$

56 LOUREIRO, op. cit., p. 148.

57 Ibidem, p. 149-50.

58 lbidem, p. 150.

59 CLÈVE, Clèmerson Merlin. Elementos para um Discurso de Conceituaçāo do Direito Administrativo. Campinas: Julex Livros, 1988, p. 49.

60 Ibidem, p. 50. Cf. Ibidem, p. 41-50. Quanto à soberania da vontade popular, frise-se, é necessário concebê-la "a partir de uma conscientização das massas populares", ou seja, de um "processo de desenvolvimento social que recusa a alienação" e reage contra os meios de controle ideológico. COELHO, Luiz Fernando. Teoria Crítica do Direito. 2. ${ }^{a}$ ed. Porto Alegre: Sergio Antonio Fabris Editor, 1991, p. 384-5.

61 LOUREIRO, op. cit., p. 151.

62 BUENO, op. cit., p. 363. 
Já no que se refere à alternativa jurídica, sua adoção, desde que vinculada aos limites definidos pelos direitos e garantias constitucionais, bem como, especificamente, pelo princípio da legalidade insculpido no artigo 37 , não é, em si, danosa ao ordenamento. Ao contrário, em algumas situações contribui para a agilidade do andamento processual garantindo os direitos do cidadão, na medida em que permite ao administrador interpretar a finalidade social que sua atuação exige. Conforme LOUREIRO, "a informalização significa um 'soft law' que contribui para a necessária flexibilização da decisão administrativa". ${ }^{63}$

Sobretudo em situações que não exigem o crivo do contraditório, a informalização, dentro dos limites constitucionais, pode garantir decisão mais rápida e de melhor qualidade, devendo inspirar principalmente o legislador, porquanto nesse aspecto o problema está intimamente ligado à qualidade da produção normativa, que não pode engessar a atuação da Administração Pública. Para LOUREIRO, "a dificuldade, no plano normativo, reside em encontrar um ponto óptimo de 'formalização procedimental'. Esta tanto pode provocar perturbações e custos desnecessários ao decision-making process como aparecer como elemento essencial de simplificação, ao permitir o estabelecimento de rotinas decisórias". ${ }^{64} \mathrm{Ou}$ seja, "uma certa estruturação normativa que reduza drasticamente os espaços de conformação da Administração, optando por uma hiper-rigidez procedimental, é ineficiente". ${ }^{65}$

Quando se refere aos processos administrativos, Diogo de Figueiredo MOREIRA NETO adota entendimento favorável à informalização, no sentido de permitir-se "o encontro de soluções negociadas e seguras em inúmeros casos em que há impasses decisórios à causa da multi-setorialização administrativa em curso". Além disso, o autor, numa postura contrária aos procedimentos burocráticos, lembra que os processos administrativos normativos ${ }^{66}$ "têm sido usados para a produção de decisões administrativas mais céleres e imediatamente executadas, a partir de estruturação de um processo compartilhado entre interessados, em geral versando temas complexos e relevantes que costumam ter sua solução procrastinada burocraticamente, em detrimento do interesse público (acordos substitutivos)" ${ }^{67}$

GABARDO, entretanto, é mais comedido ao analisar os decision-making process, asseverando "que não à toa têm designação inglesa e que representam os acordos procedimentais, para os quais não há vinculação. Possuem um caráter 'alternativo' em relação às formas jurídicas tradicionais, tanto que se chega a defender a sua impossibilidade de controle judicial. Nesta concepção de eficiência procedimental, as garantias podem ser subtraídas em benefício de um pretenso efeito

65 Ibidem, p. 132.

66 Para compreender o sentido em que o autor emprega as expressões processo administrativo e processo administrativo normativo, ver: MOREIRA NETO, Diogo de Figueiredo. Curso de Direito Administrativo: parte introdutória, parte geral e parte especial. Rio de Janeiro: Forense, 2002, p. 155-7.

67 Ibidem, p. 157. 
útil" ${ }^{63}$ Subscrevemos o posicionamento do autor, até mesmo porque esse movimento surgido nos Estados Unidos parte de uma visão distorcida do fenômeno burocrático (com objetivos de "desburocratização"), compreendendo-o numa visão pejorativa distante de seu significado científico consagrado por WEBER. ${ }^{69}$ Quanto à necessidade de controle judicial, é perfeito o posicionamento de GABARDO, pois, independente de outros argumentos, ${ }^{70} \mathrm{em}$ qualquer caso, a Constituição garante o acesso ao Judiciário para coibir lesão ou ameaça a direito (art. $5^{\circ}, \mathrm{XXXV}$ ).

A necessidade de formas rígidas, entretanto, não é a tônica em todos os procedimentos, sendo mais importante na espécie que aqui se designa como processo administrativo, marcada pela existência de partes em contraditório. Por essa razão, concordamos com o posicionamento de LOUREIRO, ao entender que "é preciso ter presente a historicidade do princípio e a necessidade de uma nova 'sensibilidade interpretativa' (ISENSEE). Assim, informalização não terá de ser sinônimo de retrocesso no programa do Estado de Direito ou uma contradictio in adjecto". ${ }^{71}$

Encontrar um ponto de equilíbrio entre formal e informal, no que se refere ao procedimento administrativo, ademais, é tarefa árdua, mas já iniciada pelos administrativistas, como é o caso de Bandeira de MELLO, ao abordar o princípio do informalismo:

Principio do informalismo, a ser considerado em favor do administrado, como querem Gordillo e Escola, significa que a administração não poderá ater-se a rigorosismos formais ao considerar as manifestações do administrado.

Assim, conforme exemplário deste último autor, se alguém entra com recursos nominando-o erradamente ou serve-se de um quando o tecnicamente cabível seria outro, ou se propõe sua petição ou alegação de prova em formulação não ortodoxa, a Administração não deve mostrar-se rigorosa, mas flexível, para aceitar tais impropriedades. A ser de outro modo observa Gordillo - , a gente simples e humilde que pleiteia algo da Administração ou que perante ela queira fazer valer seus direitos ficaria desatendida, peiada nos rigores do formalismo. ${ }^{72}$

68 GABARDO, Principio..., p. 123.

69 Nesse sentido ver: CHICÓSKI, op. cit., p. 22-25. MEDAUAR aborda o tema, apontando que: "O movimento de desregulamentação surgiu nos Estados Unidos, em meados da década de 70, com o objetivo de aliviar o peso das regras editadas pelas agencies e comissões, devolvendo aos agentes econômicos, principalmente, maior margem de liberdade de atuaçăo; o movimento expandiu-se para grande número de países, abrangendo vários setores de atividades, adquirindo também o sentido de simplificação e de redução de regulamentos, apresentando-se, assim, como uma das soluções para o problema da inflação jurídica ou inflação legislativa. No âmbito do processo jurisdicional expressou-se como deformalização; na Administração Pública, como desburocratização". MEDAUAR, op. cit., p. 122.

70 No que tange ao controle do ato discricionário pela função jurisdicional, ver: MELLO, Discricionariedade..., passim.

71 LOUREIRO, op. cit., p. 155.

72 MELLO. Curso..., p. 435. 
$\mathrm{Na}$ visão da Professora Odete MEDAUAR, em relação ao processo administrativo não deve haver propriamente informalismo, mas formalismo moderado, já que o processo comporta ritos e formas. Em suas palavras, o princípio do formalismo moderado consiste, primeiramente, "na previsão de ritos e formas simples, suficientes para propiciar um grau de certeza, segurança, respeito aos direitos dos sujeitos, o contraditório e a ampla defesa". Além disso, em segundo lugar, importa na "exigência de interpretação flexível e razoável quanto a formas, para evitar que estas sejam vistas como um fim em si mesmas, desligadas das verdadeiras finalidades do processo". Por tais razões, o princípio de modo algum pode servir de pretexto para desrespeitar exigências do contraditório e da ampla defesa. Seu objetivo é "impedir as minúcias e pormenores não essenciais afastem a compreensão da verdadeira finalidade de atuação". ${ }^{73}$

DI PIETRO, por sua vez, também se posicionou acerca do tema, especificamente quando se refere ao princípio da obediência à forma e aos procedimentos, entendendo que "informalismo não significa, nesse caso, ausência de forma; o processo administrativo é formal no sentido de que deve ser reduzido a escrito e conter documentado tudo o que ocorre no seu desenvolvimento; é informal no sentido de que não está sujeito a formas rígidas". Além disso, frisa a autora que, quando a lei estabelece procedimentos mais rígidos, "isso ocorre como garantia para o particular de que as pretensões confiadas aos órgãos administrativos serão solucionadas nos termos da lei; além disso, constituem o instrumento adequado para permitir o controle administrativo pelos Poderes Legislativo e Judicial". Donde se infere que nem todos os procedimentos requerem formas rígidas, mas principalmente aqueles que ora denominamos de processos administrativos. Para DI PIETRO, "a necessidade de maior formalismo existe nos processos que envolvem interesses dos particulares, como é o caso dos processos de licitação, disciplinar e tributário". ${ }^{74} \mathrm{E}$ conclui: "Na realidade, o formalismo somente deve existir quando seja necessário para atender ao interesse público e proteger o interesse dos particulares". ${ }^{75}$

Egon Bockmann MOREIRA assume a necessidade de ponderação entre formalização e informalização - ao tratar da simplicidade como característica da eficiência processual administrativa, conforme mencionamos acima -, dependendo de qual alternativa seja melhor para garantir os direitos do cidadão. “Ou seja, as formalidades processuais dirigem-se fundamentalmente à garantia de direitos, ao passo que o exercício deles deve ser encarado de modo generoso. O formalismo

73 MEDAUAR, op. cit., p. 122. Para a autora, são finalidades do processo administrativo, além da legitimação do poder: garantia, melhor conteúdo das decisões, eficácia das decisões, correto desempenho da função, justiça na Administração, aproximação entre Administração e cidadãos, sistematização de atuações administrativas, facilitação do controle da Administração e aplicação dos princípios e regras comuns da atividade administrativa. Ibidem, p. 43-69.

74 DI PIETRO, op. cit., p. 512. Frise-se, também em relação a esta autora, que seu posicionamento em relação à dicotomia processo-procedimento é diverso do adotado neste estudo. Cf. ibidem, p. 506-7.

75 Ibidem, p. 513. 
presta-se à segurança das pessoas privadas envolvidas no processo administrativo, não para impedir o processamento de seus pleitos". ${ }^{76}$

Impende asseverar que a questão do equilibrio entre formal e informal deve passar, necessariamente, pelo crivo da Constituição. Na medida em que a relação eficiência-procedimento se forma em dois planos distintos - normativo e administrativo $^{77}$ - o que se alia ao fato de que, neste segundo plano, "a possibilidade de uma conformação mais ou menos eficiente coloca-se nas zonas de discricionariedade administrativa", ${ }^{78}$ é possível observar que o problema está em se dizer com segurança até onde vai a discricionariedade do administrador. E, indubitavelmente, desde o ponto de vista jurídico, a resposta somente pode ser encontrada no texto constitucional. ${ }^{79}$ BACELLAR FILHO, problematizando o tema a partir do pensamento de Günter PÜTTNER, ensina que o Estado Democrático de Direito busca equilíbrio entre a ordem legítima (informal) e a ordem legal (formal):

Para Günter PÜTTNER, o Estado de Direito deve realizar um justo equilíbrio entre o elemento formal (que remete ao princípio da legalidade) e o informal (que remete, no campo administrativo, à tutela da confiança, da honestidade da Administração no trato com o cidadão). Argumenta que a vida da coletividade não pode ser reduzida a uma aplicação mecânica da lei escrita, nomeadamente, em setores como a cultura, a educação, o turismo, onde prevalece o informal, o humano, o pessoal.

Contudo, a questão da relação entre o aspecto formal e o informal do Estado de Direito - verdadeiro jogo de forças interno ao processo de vinculação do agir estatal - é determinada com base no espaço que o Direito Positivo reserva a cada um. Trata-se, aqui, de examinar o caso brasileiro: a Constituição remete a um Estado de Direito estritamente formal ou dá espaço para a combinação dos elementos antes mencionados? ${ }^{80}$

76 MOREIRA, Processo Administrativo e Princípio da Eficiência..., p. 335.

77 Cf. LOUREIRO, op. cit., p. 134.

78 Ibidem, p. 135. No entanto, o autor adverte que discricionariedade e informalização não se confundem. "Assim, apenas se pode dizer que os procedimentos informais correspondem a casos típicos de discricionariedade procedimental, mas não a monopolizam". Ibidem, p. 57.

79 Quanto às normas de processo/procedimento administrativo, obviamente que elas também não escapam do crivo da Constituição, quer pelo controle concreto quer pelo controle abstrato de sua constitucionalidade.

80 BACELLAR FILHO, op. cit., p. 125. No que diz respeito ao Estado de Direito Informal, MEDAUAR faz referência a dois autores que se debruçaram sobre o tema, BERTI e PÜTTNER: "A pregação a favor do informal acarretou, por sua vez, preocupações enfeixadas em estudos sobre o Estado de direito informal, como exemplificam os trabalhos de Berti ('Stato di diritto informale', in Rivista Trimestrale di Diritto Pubblico I, 1992, pp. 3-30) e do alemão Püttner ('Lo stato di diritto informale', no periódico supracitado, pp. 31-42), nos quais se discute a contraposição do informal e formal, da substância e da forma; nesses trabalhos não se concluiu pela eliminação do formal, como parece óbvio; assim, Berti pondera que o Estado de Direito se salva distribuindo substância e forma de modo que, respeitados os princípios constitucionais, a forma seja a veste de uma racionalidade adquirida mediante a ação e o confronto real dos interesses; é bem-vindo o informal 
Sendo a resposta no sentido de que a Constituição dispõe tanto de elementos formais (do Estado de "Direito") quanto materiais (do Estado "Democrático"), conclui-se que há espaço para o informal. Contudo, não se trata de uma informalidade ajurídica, porquanto a Administração permanece vinculada à legitimidade - enquanto moralidade, impessoalidade, publicidade e eficiência -, ou seja, aos elementos materiais definidos constitucionalmente:

A Administração Pública, enquanto modo derivado de agir do Estado, permanece duplamente vinculada: à legalidade (legitimidade positivada) e à legitimidade (naquilo que não foi ou não pôde ser positivado). (...)

A Administração Pública, inserida no Estado Democrático de Direito, não pode ter como único princípio de ação o da legalidade. A Constituição de 1988 torna nítida esta intenção ao afirmar cinco princípios constitucionais administrativos: legalidade, moralidade, impessoalidade, publicidade e eficiência. ${ }^{81}$

O que fica da breve exposição sobre as tentativas de informalização é a necessidade de equilíbrio entre a eficiência, aqui vista como informalismo, e o procedimento formal, a fim de não se impedir que o cidadão exerça seus direitos seja pela ausência de formas preestabelecidas, seja pelo seu excesso, o que, nesta última hipótese, acarretaria verdadeira barreira, principalmente para aqueles que não detêm o conhecimento burocrático ao qual WEBER já se referia. Sob a perspectiva do ordenamento jurídico brasileiro, o problema deve ser enfrentado à luz da Constituição, porquanto é esta que estabelece os direitos e garantias e, logo, os casos nos quais se deve assegurar o procedimento formal. ${ }^{82}$

no direito e no Estado se isso representa a passagem para formas jurídicas menos invasivas, inimigas do privilégio e aliadas da liberdade e do direito das pessoas (op. cit., pp. 6 e 30); de seu lado, Püttner afirma que o agir informal do Estado de Direito não pode eliminar a lei, diminuir os direitos de terceiros e acabar por usurpar competências; o Estado de direito não pode renunciar ao elemento formal e às decisões formais; deve-se encontrar o justo equilíbrio entre formal e informal (op. cit., p. 42)". MEDAUAR, op. cit., p. 122-3.

81 BACELLAR FILHO, op. cit., p. 129. A relação informalismo-legitimação adotada pelo autor, é necessário ressalvar, não parte da definição fática e procedimental de legitimação defendida por LUHMANN, à qual nos reportamos em outro artigo (CHICÓSKI, op. cit., p. 28-35), mas, antes disso, de uma definição que não prescinde da formação do consenso materialmente democrático. Cf. Ibidem, p. 126-137. O Prof. BACELLAR FILHO conclui da seguinte forma seu raciocínio: "O Estado Democrático de Direito busca equilíbrio entre a ordem legítima e a ordem legal, entre a informalidade e a formalidade normativas. Consiste fórmula conciliadora entre termos em constante tensão: o poder da maioria democrática e as regras formadoras da essência do Estado de Direito. A conciliação é exigida para que ambos não se anulem e não vigore, isoladamente, a legalidade ou a legitimidade. Enfim, a maioria legitimada pelo processo democrático precisa estar consciente dos postulados da própria democracia e do Estado de Direito". Ibidem, p. 136.

82 Numa perspectiva teórico-crítica, talvez a resposta em relação ao procedimento informal esteja na distinção que usualmente se faz entre a necessidade de formas (através das quais o direito capta a realidade, garantindo as expectativas ou, em outras palavras, gerando "segurança jurídica") e o mal do formalismo (o qual se relaciona ao dogmatismo, enquanto uma "miopia" do sistema, que 
Para que o procedimento administrativo e a eficiência convivam num ambiente estável dentro do sistema jurídico, é indispensável que esta, caracterizada como princípio, seja encarada sob a ótica da Constituição, tanto no que se refere aos demais princípios constitucionais, quanto no que tange ao Estado Social e Democrático de Direito. Se assim observada, é inegável a importância jurídica da eficiência, porquanto passa a auxiliar na maximização dos direitos e garantias constitucionalmente assegurados.

Procedimento e processo administrativos são mecanismos de garantia do cidadão e, por isso, não podem ser livremente manipulados por pretensões de eficiência. Porém, nos procedimentos administrativos em sentido estrito há sensível abertura para a influência do princípio constitucional da eficiência, notadamente no âmbito normativo, pois, quanto mais céleres, simples e econômicos, mais acessíveis eles se tornam à população, a qual na maioria das vezes não está em contraditório, nem com a Administração nem com outros cidadãos, mas apenas pleiteando a efetivação de seus direitos constitucionalmente assegurados. Já na espécie processo administrativo, ante o maior grau de incerteza e a relação contraditória dos participantes, a eficiência jamais pode servir de pretexto à supressão das garantias do contraditório e da ampla defesa. Sua finalidade é ampliá-los, mediante atributos tais como celeridade, simplicidade, finalidade predefinida, economia e efetividade do processo administrativo.

Informalização do procedimento não pode ser sinônimo de desrespeito às regras legais e, muito menos, aos mandamentos constitucionais. Sua definição deve impedir o formalismo - visto este como extravagância formal em detrimento dos direitos substanciais reclamados pela sociedade. Nessa medida, propõe-se que formal e informal se equilibrem de acordo com o sistema jurídico-constitucional, em favor do Estado Social e Democrático de Direito.

\section{Referências}

AZEVEDO, Plauto Faraco de. Crítica à Dogmática e Hermenêutica Jurídica. Porto Alegre: Sergio Antonio Fabris Editor, 1989.

deixa de enxergar a realidade social), tão bem estudada pelos críticos do positivismo jurídico. Plauto Faraco de AZEVEDO, refutando o cientificismo que marcou o direito, sobretudo após a Teoria Pura de KELSEN, afirma que houve uma redução gnoseológica, a qual "resultou na elaboração de um discurso flagrantemente ideológico, que termina por desembocar no formalismo lógico-jurídico, cuja premissa fundamental consiste justamente na pretensão de conhecimento do direito separado de toda e qualquer ideologia. Nessas condiçōes, o estudo e a investigação do direito se realizam em um sistema fechado, cujos pressupostos são aprioristicamente tidos como verdadeiros e cujo objeto mostra-se imune à crítica e distante dos problemas sociais reais". AZEVEDO, Plauto Faraco de. Crítica à Dogmática e Hermenêutica Jurídica. Porto Alegre: Sergio Antonio Fabris Editor, 1989, p. 21. A lição é válida, na medida em que não podemos, ao tentar escapar da ideologia neoliberal, retornar ao dilema do direito concebido enquanto sistema fechado e, portanto, distante da sociedade e sujeito a qualquer ideologia dominante. 
BACELlAR FILHO, Romeu Felipe. Princípios Constitucionais do Processo Administrativo Disciplinar. São Paulo: Max Limonad, 1998.

BUENO, Vera Scarpinella. "As Leis de Procedimento Administrativo: uma leitura operacional do princípio constitucional da eficiência." In: SUNFELD, Carlos Ari; MUÑOS, Guillermo Andrés (Coords.). As Leis de Processo Administrativo. São Paulo: Malheiros, 2000.

CHICÓSKI, Davi. Burocracia e Legitimação: fundamentos do procedimento administrativo eficiente. In: $A \& C$ Revista de Direito Administrativo e Constitucional. Belo Horizonte: Fórum, n. 15, p. 19-38, jan./mar., 2004.

CLÈVE, Clèmerson Merlin. Elementos para um Discurso de Conceituação do Direito Administrativo. Campinas: Julex Livros, 1988.

COELHO, Luiz Fernando. Teoria Crítica do Direito. $2^{\mathrm{a}}$ ed. Porto Alegre: Sergio Antonio Fabris Editor, 1991.

DI PIETRO, Maria Silvia Zanella. Direito Administrativo. 14. ed. São Paulo: Atlas, 2002.

FAZZIO JÚNIOR, Waldo. Fundamentos de Direito Administrativo. São Paulo: Atlas, 2001.

GABARDO. Eficiência e Legitimidade do Estado: uma análise das estruturas simbólicas do direito político. Barueri: Manole, 2003, p. 175. Cf. Ibidem, p. 171-85. 2002.

GOMES, Manoel Eduardo Alves de Camargo e. "Apontamentos sobre alguns impactos do projeto neoliberal no processo de formação de tutelas jurídico-políticas". In: MARQUES FILHO, Agostinho Ramalho; et. al. Direito e Neoliberalismo: elementos para uma leitura interdisciplinar. Curitiba: EDIBEJ, 1996, p. 129.

GORDILLO, Agustín A. "La Garantía de Defensa como Principio de Eficacia en el Procedimiento Administrativo". In: Revista de Direito Público. São Paulo: Revista dos Tribunais, n. 10, p. 16-24, out./dez., 1969.

LOUREIRO, João Carlos Simões Gonçalves. "O Procedimento Administrativo entre a Eficiência e a Garantia dos Particulares: algumas considerações". In: Boletim da Faculdade de Direito de Coimbra. Coimbra: Coimbra Editora, 1995.

MEDAUAR, Odete. A Processualidade no Direito Administrativo. São Paulo: Revista dos Tribunais, 1993.

MEIRELLES, Hely Lopes. Direito Administrativo Brasileiro. 22. ed. São Paulo: Malheiros, 1997.

MELLO, Celso Antônio Bandeira de. Discricionariedade e Controle Jurisdicional. 2. ed. 4. tiragem. São Paulo: Malheiros, 2000.

Curso de Direito Administrativo. 12 $2^{\mathrm{a}}$ ed. São Paulo: Malheiros, 2002.

MODESTO, Paulo. Notas para um Debate sobre o Princípio Constitucional da Eficiência. In: http.//www.jus.com.br/doutrina/prefici3.html". Acesso em 20/08/2002.

MOREIRA, Egon Bockmann. "Processo Administrativo e Princípio da Eficiência". In: SUNFELD, Carlos Ari; MUÑOZ, Guillermo Andrés (Coords.). As leis de processo administrativo: Lei Federal $9.784 / 99$ e Lei Paulista 10.177/98. São Paulo: Malheiros, 2000. 
Processo Administrativo: Princípios Constitucionais e a Lei 9.784/99. São Paulo: Malheiros, 2000.

MOREIRA NETO, Diogo de Figueiredo. Curso de Direito Administrativo: parte introdutória, parte geral e parte especial. Rio de Janeiro: Forense, 2002.

NEVES, Marcelo. A Constitucionalização Simbólica. São Paulo: Acadêmica, 1994.

OFFE, Claus. Problemas Estruturais do Estado Capitalista. Tradução de Bárbara Freitag. Rio de Janeiro: Tempo Brasileiro, 1984.

PEREIRA, Luiz Carlos Bresser. "Gestão do setor público: estratégia e estrutura para um novo Estado". In: PEREIRA, Luiz Carlos Bresser; SPINK, Peter (Orgs.). Reforma do Estado e Administração Pública Gerencial. 4. ed. Rio de Janeiro: Fundação Getúlio Vargas, 1998.

SOUSA, António Francisco de. "Os 'Conceitos Legais Indeterminados' no Direito Administrativo Alemão". In: Revista de Direito Administrativo. Rio de Janeiro: Fundação Getúlio Vargas, v. 166, p. 276-91, out./dez., 1986.

TÁCITO, Caio. "A Reforma do Estado e a Modernidade Administrativa". In: Revista de Direito Administrativo. Rio de Janeiro: Renovar, n. 215, p. 1-7, jan./mar., 1999.

. O Retorno do Pêndulo: "Serviço Público e Empresa Privada. O Exemplo Brasileiro". In: Revista de Direito Administrativo. Rio de Janeiro: Renovar, n. 202, p. 1-10, out./dez., 1995. 